\title{
Levels of Partnership between Nurses and Parents of Hospitalized Children and the Quality of Pediatric Nursing Care as Perceived by Nurses
}

\author{
So Yeon Yoo ${ }^{1}$, Haeryun $\mathrm{Cho}^{2}$, Yae Young Kim³ ${ }^{3}$ Ji Hyeon Park ${ }^{4}$ \\ ${ }^{1}$ Associate Professor, Department of Nursing, Kyungil University, Gyeongsan; ${ }^{2}$ Associate Professor, Department of Nursing, Wonkwang University, Iksan; \\ ${ }^{3}$ Lecturer, Department of Nursing, Chung-ang University, Seoul; ${ }^{4}$ Master's Student, Department of Nursing, Wonkwang University, Iksan, Korea
}

Purpose: This study investigated the relationship of the partnership between nurses and parents of hospitalized children with the quality of pediatric nursing care as perceived by pediatric nurses. Methods: A cross-sectional descriptive study was conducted among 90 nurses. The data collected were analyzed using the independent t-test and the Pearson correlation coefficient. Results: The level of partnership between nurses and parents showed significant differences by nurses' age ( $\mathrm{t}=2.22$, $p=.029)$ and marital status ( $\mathrm{t}=2.54, p=.013)$. The quality of pediatric nursing care was found to significantly differ by the nurses' age $(\mathrm{t}=2.62, p=.013)$, marital status $(\mathrm{t}=4.17, p<.001)$, whether nurses had children $(\mathrm{t}=2.53, p=.020)$, pediatric ward work experience $(\mathrm{t}=2.43, p=.020)$, and total work experience $(\mathrm{t}=2.51, p=.016)$. The level of partnership between nurses and parents was positively correlated with the quality of pediatric nursing care $(\mathrm{r}=.48, p<.001)$. Conclusion: To improve the quality of nursing care for hospitalized children and their parents, it is important to consider the specific characteristics of pediatric nurses, whose clinical skills should be improved.

Key words: Nurse specialists; Pediatric nursing; Quality of health care

\section{Corresponding author Haeryun Cho}

https://orcid.org/0000-0001-7366-9774

Department of Nursing, Wonkwang University,

460 Iksandae-ro, Iksan 54538, Korea

TEL +82-63-850-6020 FAX +82-63-850-6060

E-MAIL chr@wku.ac.kr

*This study was supported by the research fund of Wonkwang University in 2018.

Received Nov 1, 2019 Revised Dec 20, 2019 Accepted Dec 30, 2019 (a) This is an Open Access article distributed under the terms of the Creative Commons Attribution NonCommercial License (http://creativecommons.org/licenses/by-nc/4.0/) which permits unrestricted noncommercial use, distribution, and reproduction in any medium, provided the original work is properly cited.

\section{INTRODUCTION}

Family-centered care, which supports and respects family involvement in all aspects of the child's health care, has been established as a philosophy of pediatric care. Both the American Academy of Pediatrics and the Association for the Care of Children's Health in USA use family-centered care as a standard for pediatric health care [1]. In other words, for children to achieve optimal growth and development and for children's health capacity to be maximized, it is necessary to provide high-quality professional nursing care that is grounded in interactions between nurses and parents in the family context $[2,3]$. Therefore, the preferences and values of children and their families should be considered when providing nursing care in pediatric wards $[4,5]$.

Studies have shown that family-centered care results in positive outcomes and experiences for hospitalized children and their families, improves satisfaction among health professionals, and reduces medical costs [6]. Several studies have been conducted of pediatric nurses in various nations, examining their attitudes and perceptions towards family-centered care in pediatric wards [3,7-9], pediatric intensive care units [10], and pediatric cancer units [11].

While an increasing amount of research has focused on family-centered care in Korea, for the most part this research 
has consisted of conceptual analyses and the development of instruments related to family-centered care [4,12-14]. It is not enough to elicit implications, because these efforts have not yielded results that can be applied directly to the clinical field. In particular, considering the cultural background of Korea, where inpatient care for children has traditionally been provided in an environment where one parent or family member resides in a pediatric ward, it is necessary to determine nurses' specific knowledge of family-centered care, rather than accepting the results of international studies conducted among participants with different cultural backgrounds. A recent study that analyzed the perceptions of family-centered care of children and adolescents among health professionals in Korea [15] partially elicited the attributes of family-centered care, but the participants' perceptions of family-centered nursing were insufficient.

Although domestic and international studies have claimed that family-centered care remains an abstract concept in the actual clinical field $[3,5,7,16]$, nurses' efforts to improve the quality of nursing based on family-centered care are essential in the clinical practice of child nursing. To this end, cooperative partnerships between nurses and families are a vital factor $[5,11]$. It is essential for nurses to establish a stable and equal partnership with children's parents to facilitate highquality care in pediatric wards $[4,17]$.

Cooperative partnerships between pediatric nurses and children's parents, which develop through systematic and regular interactions, allow them to provide the best care for children $[18,19]$, and pediatric nurses and parents of hospitalized children can build successful partnerships by sharing their knowledge, skills, and resources, thereby improving the quality of care of hospitalized children [11]. In other words, nurses' efforts to establish partnerships with the parents of hospitalized children based on family-centered care promote improvements in the quality of pediatric ward nursing. Therefore, pediatric nurses should respect the wishes of hospitalized children and their families and provide sufficient explanations to ensure their informed participation in nursing care.

Specifically, pediatric nurses should carry out their responsibilities and engage in collaborative decision-making, while providing nursing care that shows respect for hospitalized children and their families. It is also necessary for pediatric nurses to be sensitive to families' needs, as this allows families to play their most important role of care providers, ensuring parental autonomy and decision-making related to hospitalized children [1,5]. Patients and their families must make decisions and participate to the extent that they choose, and it is recommended that nurses actively support them in doing so $[20,21]$. The involvement of patients and families in the nursing process not only affects the outcome of disease treatment, but also promotes significant improvements in the quality of care [17]. Therefore, factors such as respect for patients and families, accurate information, a warm and kindly attitude, and the skilled performance of nursing tasks are important for the quality of care.

As such, the directions in which pediatric nurses should focus their efforts to improve the quality of pediatric ward nursing have been confirmed in detail. However, in earlier studies concerning the quality of nursing care in pediatric wards and partnerships with nurses as analyzed by the mothers of inpatient children [22], the quality of nursing care recognized by mothers of hospitalized children [23], and comparisons of the quality of nursing care perceived by the mothers of hospitalized children and the respective nurses [16], there were limitations in terms of examining the quality of nursing and the partnership with hospitalized children's parents from the perspective of nurses.

The quality of nursing care in pediatric wards depends on purpose-oriented nurses' behavior to promote the well-being of inpatient children and their families [4,24], and perceptions of the quality of care might differ between nursing providers and the recipients of care [16]. Therefore, basic research to confirm the perceptions of nursing providers is necessary. In addition, it is essential to obtain concrete results to help nurses establish direct strategies for improving the quality of nursing.

This aim of this study was to determine the relationship of the partnership between nurses and parents of hospitalized children with the quality of family-centered care as perceived by pediatric nurses. Ultimately, this study sought to obtain a better understanding of pediatric nursing care and to identify strategies for improving the quality of family-centered care for hospitalized children.

\section{Purpose}

The purpose of this study was to examine the partnership between nurses and parents of hospitalized children and the quality of pediatric nursing care as perceived by pediatric nurses.

The specific aims were as follows:

- To determine the general characteristics of pediatric nurses.

- To characterize the level of partnership between nurses and parents of hospitalized children and the quality of pediatric nursing care (respect, explanation, kindness, skillfulness) as perceived by the pediatric nurses.

- To identify differences in the level of partnership between nurses and parents of hospitalized children and 
the quality of pediatric care (respect, explanation, kindness, skillfulness) according to the general characteristics of pediatric nurses.

- To identify correlations of the level of partnership between nurses and parents of hospitalized children with the quality of pediatric nursing care (respect, explanation, kindness, skillfulness).

\section{METHODS}

\section{Design}

A cross-sectional descriptive study design was utilized to investigate the partnership between nurses and the parents of hospitalized children and the quality of pediatric nursing care.

\section{Participants}

The population of this study comprised nurses working in pediatric wards. The inclusion criterion was nurses required to provide direct nursing care for hospitalized children and their families. Managers and other individuals who did not directly work with hospitalized children and their families were excluded, as were nurses working in the neonatal intensive care unit, pediatric intensive care unit, and pediatric cancer ward.

The sample size required for this study was calculated using the $\mathrm{G}^{*}$ Power 3.1.3 program [25]. In the correlation analysis, 84 samples were required for the desired medium effect size (.30) with a significance level of .05 and power of .80. In total, 90 nurses were surveyed with due consideration of possible dropout. All of the questionnaires that were distributed were collected, and all the collected data were used for the analysis.

\section{Measurement}

\section{1) Partnership between nurses and parents of hospitalized chil- dren}

The instrument used in this study was the Pediatric Nurse Parent Partnership scale developed by Choi and Bang [2], which includes 34 questions scored on a 5-point Likert scale; the total score ranges from 34 to 170, with a higher score indicating a more positive partnership between the parent and nurse. The Cronbach's $\alpha$ of the scale at the time of its development was .92 [2], and it was .96 in this study. This tool was approved for use by its developers.

\section{2) Quality of pediatric nursing care}

The instrument used in this study was the Quality of Care through Patients' Eyes for Hospitalized Children developed by Cho et al. [4] for the parents of hospitalized children. This scale was modified by Yoo et al. [16] for pediatric nurses and tested for content validity and reliability. In total, 19 items were included: six items focusing on respect, three items on kindness, seven items on explanation, and three items on skillfulness. For each item, importance and performance are measured on a 4-point Likert scale. The importance score is as follows: not important, 0 point; slightly important, 3 points; important, 6 points; very important, 10 points. The performance score is as follows: no, 1 point; generally no, 0.67 points; generally yes, 0.33 points; and yes, 0 point. The score for the quality of pediatric care was calculated as 10 - (importance score $\times$ performance score), yielding a total score ranging from 0 to 10 , with higher scores corresponding to higher-quality pediatric nursing care. The value of Cronbach's $\alpha$ was reported to be .94 for importance and .92 for performance [16]. The Cronbach's $\alpha$ in this study was .92 for importance and .91 for performance. This tool was approved for use by its developers.

\section{Data Collection and Ethical Considerations}

After obtaining approval from the Institutional Review Board of W University (IRB No. WKIRB-21710-SB-077), this study was conducted between September 24, 2018, and October 19, 2018. Participants were employed in the pediatric wards of two university hospitals in Seoul, one university hospital in Gyeongsang Province, and two university hospitals in Jeolla Province. The researchers visited the wards to administer the questionnaire. The participants were provided with an explanation of the purpose of this study before they agreed to participate, and allowed to choose between voluntary consent and refusal to participate. The questionnaire took approximately 10 minutes to complete. After the questionnaire was completed, each respondent received approximately 8 USD worth of goods as a token of appreciation.

\section{Data Analysis}

The data were analyzed using IBM SPSS Statistics 24 (IBM Corp., Armonk, NY, USA). The participants' general characteristics, level of partnership between nurses and parents of hospitalized children, and quality of pediatric nursing care were analyzed using frequencies, percentages, means, and standard deviations. The independent $\mathrm{t}$-test was used to compare the level of partnership between nurses and parents of hospitalized children and the quality of pediatric nursing care according to nurses' general characteristics, and the Pearson correlation coefficient was used to assess the correlations of 
the level of partnership between nurses and parents of hospitalized children with the quality of pediatric nursing care.

\section{RESULTS}

\section{General Characteristics of the Participants}

The general characteristics of the participants are shown in Table 1 . The average age of the participants was $28.9 \pm 7.1$ years. Overall, $61.2 \%$ of the nurses were unmarried and $82.2 \%$ did not have children. Furthermore, $60.0 \%$ had an undergraduate degree and $63.4 \%$ reported no religious affiliation. The participants' average pediatric ward work experience was $4.2 \pm 5.4$ years, while their average total work experience was

Table 1. General Characteristics of the Participants

$(N=90)$

\begin{tabular}{llc}
\hline Characteristics & Categories & $\mathrm{n}(\%)$ or M \pm SD \\
\hline Age (year) & $\leq 29$ & $64(71.1)$ \\
& $\geq 30$ & $26(28.9)$ \\
Marital status & Married & $28.9 \pm 7.1$ \\
& Not married & $22(19.8)$ \\
Having children & One child & $68(61.2)$ \\
& Two children & $11(12.2)$ \\
& None & $5(5.6)$ \\
Education & College & $74(82.2)$ \\
& Undergraduate & $32(35.6)$ \\
& Graduation & $54(60.0)$ \\
Religion & Christian & $4(4.4)$ \\
& Catholic & $17(18.9)$ \\
& Buddhism & $3(11.1)$ \\
Won Buddhism & $3(3.3)$ \\
(year) & No religion & $57(63.4)$ \\
& $\leq 4.15$ & $62(68.9)$ \\
Pediatric ward work & $\geq 4.16$ & $28(31.1)$ \\
experience (year) & & $4.2 \pm 5.4$ \\
& & $60(66.7)$ \\
& & $30(33.3)$ \\
& & $6.4 \pm 7.3$ \\
\hline
\end{tabular}

6.4 \pm 7.3 years (Table 1$)$.

\section{Partnership between Nurses and Parents of Hospitalized Children and Quality of Pediatric Nursing Care}

The average score for partnership between nurses and parents of hospitalized children was $3.88 \pm 0.45$ points out of 5.00 . The mean score for the quality of pediatric nursing care was $8.07 \pm 0.81$ points out of 10.00 . The mean scores for the subcategories of respect, explanation, kindness, and skillfulness were $8.11 \pm 0.95,8.19 \pm 0.92,8.12 \pm 1.13$, and $7.67 \pm 1.26$ points, respectively (Table 2 ).

\section{Differences in the Partnership between Nurses and Parents of Hospitalized Children and Quality of Pe- diatric Nursing Care by General Characteristics}

Table 3 shows differences in the level of partnership between nurses and parents of hospitalized children and the quality of pediatric nursing care by the participants' general characteristics. The partnership between nurses and parents of hospitalized children differed significantly depending on the nurses' age $(t=2.22, p=.029)$ and marital status $(t=2.54, p=$ .013). There appeared to be no significant difference according to the nurses' pediatric ward work experience or total work experience (Table 3).

Variables for which the quality of pediatric nursing care differed significantly were nurses' age $(t=2.62, p=.013)$, marital status $(\mathrm{t}=4.17, p<.001)$, having children $(\mathrm{t}=2.53, p=.020)$, pediatric ward work experience $(\mathrm{t}=2.43, p=.020)$, and total work experience $(t=2.51, p=.016)$. Among the subcategories of quality of care, the quality of respect differed significantly by age $(\mathrm{t}=3.28, p=.001)$, marital status $(\mathrm{t}=4.81, p<.001)$, having a child $(\mathrm{t}=3.40, p=.001)$, and total work experience $(\mathrm{t}=3.00$, $p=.004)$; the quality of explanation by marital status $(\mathrm{t}=2.84$, $p=.008)$, and pediatric ward work experience $(\mathrm{t}=3.22, p=.002)$; and the quality of skillfulness by age $(\mathrm{t}=3.31, p=.001)$, marital status $(\mathrm{t}=5.34, p<.001)$, having a child $(\mathrm{t}=3.75, p<.001)$, and total work experience $(\mathrm{t}=3.18, p=.002)$ (Table 3$)$.

Table 2. Level of Partnership between Nurses and Parents of Hospitalized Children and the Quality of Pediatric Nursing Care ( $N=90)$

\begin{tabular}{lcccc}
\hline Variables and categories & Range & Min & Max & M SD \\
\hline Partnership between nurses and parents of hospitalized children & $1 \sim 5$ & 2.76 & 4.94 & $3.88 \pm 0.45$ \\
Quality of pediatric nursing care & $1 \sim 10$ & 6.36 & 10.00 & $8.07 \pm 0.81$ \\
$\quad$ Respect & $1 \sim 10$ & 5.78 & 10.00 & $8.11 \pm 0.95$ \\
$\quad$ Explanation & $1 \sim 10$ & 6.49 & 10.00 & $8.19 \pm 0.92$ \\
$\quad$ Kindness & $1 \sim 10$ & 4.19 & 10.00 & $8.12 \pm 1.13$ \\
$\quad$ Skillfulness & $1 \sim 10$ & 3.99 & 10.00 & $7.67 \pm 1.26$ \\
\hline
\end{tabular}




\section{Correlations of the Partnership between Nurses and Parents of Hospitalized Children with the Quality of Pediatric Nursing Care}

Table 4 shows the correlations of the level of partnership between nurses and parents of hospitalized children with the quality of pediatric nursing care. The level of partnership be- tween nurses and parents of hospitalized children was positively correlated with the quality of pediatric nursing care $(\mathrm{r}=.48, p<.001)$, the quality of respect $(\mathrm{r}=.47, p<.001)$, the quality of kindness $(\mathrm{r}=.41, p<.001)$, and the quality of skillfulness $(\mathrm{r}=.41, p<.001)$. Although a low correlation coefficient was found for the quality of explanation $(\mathrm{r}=.27, p=.009)$, the correlation was statistically significant (Table 4 ).

Table 3. Differences in the Level of Partnership between Nurses and Parents of Hospitalized Children and the Quality of Pediatric Nursing Care by General Characteristics

$(N=90)$

\begin{tabular}{|c|c|c|c|c|c|c|c|}
\hline \multirow{3}{*}{ Variables } & \multirow{3}{*}{ Categories } & \multirow{3}{*}{$\begin{array}{c}\text { Partnership } \\
\text { between } \\
\begin{array}{c}\text { nurses and parents } \\
\text { of hospitalized } \\
\text { children }\end{array} \\
\mathrm{M} \pm \mathrm{SD}\end{array}$} & \multicolumn{5}{|c|}{ Quality of pediatric nursing care } \\
\hline & & & Total & Respect & Explanation & Kindness & Skillfulness \\
\hline & & & $\mathrm{M} \pm \mathrm{SD}$ & $\mathrm{M} \pm \mathrm{SD}$ & $\mathrm{M} \pm \mathrm{SD}$ & $\mathrm{M} \pm \mathrm{SD}$ & $\mathrm{M} \pm \mathrm{SD}$ \\
\hline Age (year) & $\begin{array}{l}\leq 29 \\
\geq 30 \\
\mathrm{t}(p)\end{array}$ & $\begin{array}{l}3.81 \pm 0.45 \\
4.04 \pm 0.41 \\
2.22(.029)\end{array}$ & $\begin{array}{l}7.91 \pm 0.67 \\
8.46 \pm 0.98 \\
2.62(.013)\end{array}$ & $\begin{array}{l}7.91 \pm 0.85 \\
8.60 \pm 1.02 \\
3.28(.001)\end{array}$ & $\begin{array}{l}8.09 \pm 0.82 \\
8.44 \pm 1.09 \\
1.49(.146)\end{array}$ & $\begin{array}{l}8.01 \pm 1.13 \\
8.38 \pm 1.10 \\
1.44(.154)\end{array}$ & $\begin{array}{l}7.41 \pm 1.20 \\
8.32 \pm 1.18 \\
3.31(.001)\end{array}$ \\
\hline Marital status & $\begin{array}{l}\text { Married } \\
\text { Not married } \\
\mathrm{t}(p)\end{array}$ & $\begin{array}{l}3.81 \pm 0.44 \\
4.08 \pm 0.43 \\
2.54(.013)\end{array}$ & $\begin{array}{c}7.86 \pm 0.64 \\
8.74 \pm 0.92 \\
4.17(<.001)\end{array}$ & $\begin{array}{c}7.86 \pm 0.82 \\
8.86 \pm 0.92 \\
4.81(<.001)\end{array}$ & $\begin{array}{l}8.02 \pm 0.79 \\
8.73 \pm 1.09 \\
2.84(.008)\end{array}$ & $\begin{array}{l}7.99 \pm 1.10 \\
8.50 \pm 1.16 \\
1.85(.068)\end{array}$ & $\begin{array}{c}7.32 \pm 1.10 \\
8.76 \pm 1.08 \\
5.34(<.001)\end{array}$ \\
\hline Having children & $\begin{array}{l}\text { Have } \\
\text { None } \\
\mathrm{t}(p)\end{array}$ & $\begin{array}{l}4.06 \pm 0.41 \\
3.84 \pm 0.45 \\
1.79(.077)\end{array}$ & $\begin{array}{l}8.59 \pm 0.94 \\
7.96 \pm 0.74 \\
2.53(.020)\end{array}$ & $\begin{array}{l}8.80 \pm 0.88 \\
7.96 \pm 0.90 \\
3.40(.001)\end{array}$ & $\begin{array}{l}8.51 \pm 1.13 \\
8.12 \pm 0.86 \\
1.30(.210)\end{array}$ & $\begin{array}{l}8.33 \pm 1.16 \\
8.07 \pm 1.13 \\
0.84(.401)\end{array}$ & $\begin{array}{c}8.67 \pm 1.14 \\
7.46 \pm 1.18 \\
3.75(<.001)\end{array}$ \\
\hline Education & $\begin{array}{l}\text { College } \\
\geq \text { Undergraduate } \\
\mathrm{t}(p)\end{array}$ & $\begin{array}{l}3.84 \pm 0.31 \\
3.90 \pm 0.51 \\
0.60(.548)\end{array}$ & $\begin{array}{l}8.02 \pm 0.77 \\
8.10 \pm 0.83 \\
0.43(.667)\end{array}$ & $\begin{array}{l}8.05 \pm 0.91 \\
8.14 \pm 0.97 \\
0.47(.641)\end{array}$ & $\begin{array}{l}8.11 \pm 0.85 \\
8.24 \pm 0.95 \\
0.60(.549)\end{array}$ & $\begin{array}{l}8.04 \pm 1.09 \\
8.16 \pm 1.16 \\
0.47(.640)\end{array}$ & $\begin{array}{l}7.67 \pm 1.37 \\
7.67 \pm 1.20 \\
0.01(.995)\end{array}$ \\
\hline Religion & $\begin{array}{l}\text { Yes } \\
\text { No } \\
\mathrm{t}(p)\end{array}$ & $\begin{array}{l}3.90 \pm 0.47 \\
3.87 \pm 0.45 \\
0.33(.741)\end{array}$ & $\begin{array}{l}8.10 \pm 0.85 \\
8.06 \pm 0.79 \\
0.24(.810)\end{array}$ & $\begin{array}{l}8.16 \pm 0.88 \\
8.08 \pm 0.99 \\
0.40(.692)\end{array}$ & $\begin{array}{l}8.25 \pm 0.95 \\
8.16 \pm 0.90 \\
0.45(.652)\end{array}$ & $\begin{array}{l}8.14 \pm 1.32 \\
8.10 \pm 1.01 \\
0.15(.878)\end{array}$ & $\begin{array}{l}7.55 \pm 1.29 \\
7.74 \pm 1.24 \\
0.68(.497)\end{array}$ \\
\hline $\begin{array}{l}\text { Pediatric ward } \\
\text { work experience } \\
\text { (year) }\end{array}$ & $\begin{array}{l}\leq 4.15 \\
\geq 4.16 \\
\mathrm{t}(p)\end{array}$ & $\begin{array}{l}3.83 \pm 0.42 \\
3.99 \pm 0.50 \\
1.61(.110)\end{array}$ & $\begin{array}{l}7.92 \pm 0.69 \\
8.41 \pm 0.96 \\
2.43(.020)\end{array}$ & $\begin{array}{l}7.98 \pm 0.88 \\
8.39 \pm 1.04 \\
1.95(.055)\end{array}$ & $\begin{array}{l}7.99 \pm 0.81 \\
8.63 \pm 1.00 \\
3.22(.002)\end{array}$ & $\begin{array}{l}8.03 \pm 1.08 \\
8.32 \pm 1.22 \\
1.14(.259)\end{array}$ & $\begin{array}{l}7.51 \pm 1.20 \\
8.03 \pm 1.32 \\
1.82(.072)\end{array}$ \\
\hline $\begin{array}{l}\text { Total work } \\
\text { experience } \\
\text { (year) }\end{array}$ & $\begin{array}{l}\leq 6.42 \\
\geq 6.43 \\
t(p)\end{array}$ & $\begin{array}{l}3.83 \pm 0.45 \\
3.98 \pm 0.43 \\
1.48(.142)\end{array}$ & $\begin{array}{l}7.91 \pm 0.68 \\
8.40 \pm 0.95 \\
2.51(.016)\end{array}$ & $\begin{array}{l}7.91 \pm 0.84 \\
8.51 \pm 1.03 \\
3.00(.004)\end{array}$ & $\begin{array}{l}8.07 \pm 0.84 \\
8.44 \pm 1.02 \\
1.84(.069)\end{array}$ & $\begin{array}{l}8.06 \pm 1.15 \\
8.23 \pm 1.10 \\
0.64(.521)\end{array}$ & $\begin{array}{l}7.39 \pm 1.20 \\
8.24 \pm 1.19 \\
3.18(.002)\end{array}$ \\
\hline
\end{tabular}

Table 4. Correlations of the Level of Partnership between Nurses and Parents of Hospitalized Children with the Quality of Pediatric Nursing Care

\begin{tabular}{|c|c|c|c|c|c|c|}
\hline \multirow{3}{*}{ Variable } & \multirow{3}{*}{ Categories } & \multirow{3}{*}{$\begin{array}{c}\begin{array}{c}\text { Partnership between } \\
\text { nurses and parents } \\
\text { of hospitalized children }\end{array} \\
\mathrm{r}(p)\end{array}$} & \multicolumn{4}{|c|}{ Quality of pediatric nursing care } \\
\hline & & & Total & Respect & Explanation & Kindness \\
\hline & & & $\mathrm{r}(p)$ & $\mathrm{r}(p)$ & $\mathrm{r}(p)$ & $\mathrm{r}(p)$ \\
\hline \multirow{5}{*}{$\begin{array}{l}\text { Quality of } \\
\text { pediatric } \\
\text { nursing care }\end{array}$} & Total & $.48(<.001)$ & & & & \\
\hline & Respect & $.47(<.001)$ & $.86(<.001)$ & & & \\
\hline & Explanation & $.27(.009)$ & $.82(<.001)$ & $.54(<.001)$ & & \\
\hline & Kindness & $.41(<.001)$ & $.72(<.001)$ & $.58(<.001)$ & $.44(<.001)$ & \\
\hline & Skillfulness & $.41(<.001)$ & $.77(<.001)$ & $.57(<.001)$ & $.49(<.001)$ & $.44(<.001)$ \\
\hline
\end{tabular}




\section{DISCUSSION}

This study was conducted to obtain insights into strategies for improving the quality of pediatric care based on the family-centered care model. This study analyzed the partnership between nurses and parents of hospitalized children and the quality of pediatric nursing care as recognized by nurses working in pediatric wards.

The score for partnership between nurses and parents of hospitalized children was 3.88, similar to the results of Choi and Kim [26] regarding pediatric nurses, including those in the neonatal intensive care unit, pediatric intensive care unit, pediatric emergency room, and pediatric wards. This score was a moderate level [2]. The results of this study support previous research conducted in Korea that has suggested that it is not enough for nurses to recognize and interact with the parents of hospitalized children; instead, it is very important for nurses to form a cooperative partnership with the parents of hospitalized children in order to implement family-centered care. In order to promote partnership between nurses and the parents of hospitalized children in pediatric wards, it is critical to educate pediatric nurses on the importance of interactions and cooperation.

Our results showed that the quality of pediatric nursing care was similar to that reported by Yoo et al. [16]. In terms of subcategories, the quality scores for respect, explanation, and kindness were similar, ranging from 8.11 to 8.19 , with skillfulness having the lowest quality score of 7.67. This is consistent with previous studies showing that the score for skillfulness was the lowest among the quality of care scores assessed by nurses and parents of hospitalized children [16,22, 23]. Parents of hospitalized children viewed accurate and skilled nursing techniques and prompt and meticulous interventions as the most important factor [16,23]. Many researchers have emphasized that efforts to train nurses in basic clinical skills are needed to improve the quality of nursing care $[16,22,23]$. Clinical skills are also regarded as an important component of the competence of pediatric nurses [27]. Therefore, in order to improve the quality of nursing care for hospitalized children, nurses are trained using models and simulations, affording them greater confidence in their nursing skills.

Significant differences were found in the quality of pediatric nursing care according to the nurses' age, marital status, having children, amount of work experience in the pediatric ward, and overall work experience. The quality of pediatric nursing care was significantly higher in the nurses with aboveaverage age, especially in terms of respect and skillfulness. A few previous studies have analyzed the relationships of nurses' age, pediatric ward experience, and career with quality of care. Nursing involves caring with the goal of ensuring individuals' overall well-being [28]. Over time, nurses' skill sets develop through their experience of various nursing situations and patients. The results of this study are thought to reflect the accumulation of such experiences in understanding the dignity of human beings in various situations, thereby inculcating a greater respect for patients and promoting their mastery of nursing skills. Therefore, based on the results of this study, further studies should be conducted to verify the relationships among these variables.

The quality of explanation was significantly higher among nurses with higher-than-average pediatric ward experience. A previous study that examined the nursing needs of mothers with hospitalized children reported that explanation was viewed as being equally important as skillfulness in pediatric nurses $[16,23]$. In particular, when providing care in pediatric wards, the stages of a child's cognitive development can vary, making it necessary to tailor care accordingly [28]. In addition, detailed and specific explanation are needed to elicit cooperation from the parents of children receiving inpatient care $[4,23]$. The significant differences in the quality of explanation according to the career experience of pediatric nurses reflect the characteristics of these wards.

Significant differences were found in the quality of pediatric nursing care according to marital status and having children; more specifically, the quality scores for respect and skillfulness were significantly higher among married nurses and those with children. This does not support previous research finding no relationship between marital status and quality of care [29]. This difference may be due in part to the fact that the participants of previous studies were mainly nurses of adult patients' wards. When a nurse gets married and has a child, her level of empathy depends on her personal experience, and the perceptions and attitudes of hospitalized children and caregivers may also change. However, since empirical research on the effects of marital status, caregiving, and the quality of care provided to children is limited, more research needs to be conducted before making any generalizations. There was also a significant difference in the quality of skillfulness, which may have been due to the fact that older nurses may have been more likely to be married and have children [26]. This interpretation may map on to the results of this study in terms of factors that significantly promote high-quality care.

Significant differences were found in the level of partnership between nurses and parents of hospitalized children according to the participants' age and marital status, which does not support Kang, Ahn, and Kim [30], who reported no differences according to age and work experience in pediatric wards. However, our results are consistent with those of an- 
other study [26] that married nurses displayed high levels of parental partnership. While the importance of family-centered care has emerged in inpatient care, family-centered care has not yet been established in the domestic nursing field [16]. There is a need for ongoing trials of family-centered care and research to verify these multiple perspectives.

Finally, a significant positive correlation was found between the level of partnership between nurses and parents of hospitalized children and the quality of pediatric nursing. This may have been because both the partnership between nurses and parents of hospitalized children and the quality of pediatric nursing care are based on family-centered care [2,4]. In order to improve the quality of nursing care in pediatric wards, the parents of hospitalized children should be recognized as partners in nursing care.

This study is meaningful in that it provided preliminary findings to aid in the development of strategies to improve the quality of pediatric nursing care for hospitalized children. It is important to study nurses' perceptions, as the quality of care can depend on their behavior. This study differs from previous research in that it sought to confirm nurses' perceptions of nursing quality. In addition, since pediatric nursing is based on the philosophy of family-centered care, a strength of this study is its attempt to analyze family-centered care. However, a limitation of the study is that the participants were nurses working specifically in general pediatric wards. Future research should expand to include nurses working in a variety of settings.

\section{CONCLUSION}

This study was conducted to analyze the partnership between nurses and parents of hospitalized children and the quality of pediatric nursing care as perceived by pediatric nurses. This study showed that the level of partnership between nurses and parents of hospitalized children and the quality of pediatric nursing were higher in nurses who were older, married, and with children. Additionally, the quality of pediatric nursing care was found to be higher among nurses with longer work experience in pediatric wards.

Based on the results of this study, it is necessary to keep the following considerations in mind when developing strategies to improve the quality of care for hospitalized children. First, it is necessary to improve the technical skills of pediatric nurses. Nurses who provide direct nursing care for hospitalized children should be trained in nursing skills using a variety of educational materials. In addition, studies should be conducted to develop a systematic protocol to include the parents of hospitalized children in their care and to verify its effectiveness.

\section{Conflict of interest}

No existing or potential conflict of interest relevant to this article was reported.

\section{REFERENCES}

1. Mikkelsen G, Frederiksen K. Family-centered care of children in hospital-a concept analysis. Journal of Advanced Nursing. 2011;67 (5):1152-1162. https://doi.org/10.1111/j.1365-2648.2010.05574.x

2. Choi MY, Bang KS. Development and testing of a pediatric nurse parent partnership scale. Journal of Korean Academy of Nursing. 2013;43(2):194-202. https://doi.org/10.4040/jkan.2013.43.2.194

3. Dall'Oglio I, Di Furia M, Tiozzo E, Gawronski O, Biagiolo V, Di Ciommo VM, et al. Practice and perceptions of family centered care among healthcare providers: A cross-sectional study in a pediatric hospital. Journal of Pediatric Nursing. 2018;43:e18-e25. https://doi.org/10.1016/j.pedn.2018.07.015

4. Cho H, Oh J, Jung D. Development of an instrument to measure the quality of care through patients' eyes for hospitalized child. Child Health Nursing Research. 2015;21(2):131-140.

https://doi.org/10.4094/chnr.2015.21.2.131

5 . Smith W. Concept analysis of family-centered care of hospitalized pediatric patients. Journal of Pediatric Nursing. 2018;42:57-64.

https://doi.org/10.1016/j.pedn.2018.06.014

6. Abraham M, Moretz JG. Implementing patient- and family-centered care: Part I-understanding the challenges. Pediatric Nursing. 2012;38(1):44-47.

7. Boztepe H, Kerimoğlu Yıldız G. Nurses' perceptions of barriers to implementing family-centered care in a pediatric setting: A qualitative study. Journal for Specialist in Pediatric Nursing. 2017;22 (2):e12175. https://doi.org/10.1111/jspn.12175

8. Kurtulus N, Yildiz K, Korucu E, Ozyazicioglu N. Determination of pediatric nurses' attitudes on family-centered care. International Journal of Caring Sciences. 2018;11(2):1066-1072.

9. Matziou V, Manesi V, Vlachioti E, Perdikaris P, Matziou T, Chliara JI, et al. Evaluating how paediatric nurses perceive the family-centered model of care and its use in daily practice. British Journal of Nursing. 2018;27(14):810-816.

https://doi.org/10.12968/bjon.2018.27.14.810

10. Richards CA, Starks H, O'Conner MR, Doorenbos AZ. Elements of family-centered care in the pediatric intensive care unit: An integrative review. Journal of Hospice and Palliative Nursing. 2017; 19(3):238-246. https:// doi.org/10.1097/NJH.0000000000000335

11. Salvador A, Crespo C, Barros L. The benefits of family-centered care for parental self-efficacy and psychological well-being in parents of children with cancer. Journal of Child and Family Studies. 2019;28:1926-1936. https://doi.org/10.1007/s10826-019-01418-4

12. Choi MY. Parent participation in care of hospitalized children: Concept analysis. Child Health Nursing Research. 2014;20(2):105-112. 
https://doi.org/10.4094/chnr.2014.20.2.105

13. Im M, Oh J. An integrative review on family-centered rounds for hospitalized children caring. Child Health Nursing Research. 2016; 22(2):107-116. https://doi.org/10.4094/chnr.2016.22.2.107

14. Jung SY, Tak YR. Family-centered care for hospitalized children: Concept analysis. Child Health Nursing Research. 2017;23(1):28-36. https://doi.org/10.4094/chnr.2017.23.1.28

15. Jung SY. Health care providers' perceptions of family-centered care in pediatrics. Child Health Nursing Research. 2018;24(4):465-474. https://doi.org/10.4094/chnr.2018.24.4.465

16. YooSY, Kim YY, Cho H. Comparison of the quality of nursing care as perceived by pediatric nurses and mothers of hospitalized children. Child Health Nursing Research. 2018;24(4):373-382. https://doi.org/10.4094/chnr.2018.24.4.373

17. Oh J, Cho H, Kim YY, Park HJ, Kim HK. An integrative review on development of "QUality Of care Through the patients' Eyes" (QUOTE) instrument. Journal of Nursing Care Quality. 2015;30 (4):E26-E31. https://doi.org/10.1097/NCQ.0000000000000127

18. Choi M, Bang K. Quality of pediatric nursing care: Concept analysis. Journal of Korean Academy of Nursing. 2010;40(6):757-764. https://doi.org/10.4040/jkan.2010.40.6.757

19. Millenson ML, Shapiro E, Greenhouse PK, DiGioia AM III. Patientand family-centered care: A systematic approach to better ethics and care. AMA Journal of Ethics. 2016;18(1):49-55.

https://doi.org/10.1001/journalofethics.2016.18.1.stas1-1601

20. Coyne I, Amory A, Kiernan G, Gibson F. Children's participation in shared decision-making: Children, adolescents, parents and healthcare professionals' perspectives and experiences. European Journal of Oncology Nursing. 2014;18(3):273-280. https://doi.org/10.1016/j.ejon.2014.01.006

21. Delany C, Galvin J. Ethics and shared decision-making in peadiatric occupational therapy practice. Developmental Neurorehabilitation. 2014;17(5):347-354 https://doi.org/10.3109/17518423.2013.784816
22. Bae SY, Lee I. The effect of child's mother and nurse partnership on the anxiety and perceived quality of nursing care of hospitalized child's mother. Journal of the Korea Academia-Industrial cooperation Society. 2017;18(7):516-528.

https://doi.org/10.5762/KAIS.2017.18.7.516

23. Kim YY, Cho H. A convergence study on nursing needs of hospitalized children's mothers and quality of care in pediatric unit. Journal of the Korea Convergence Society. 2017;8(10):155-166. https://doi.org/10.15207/JKCS.2017.8.10.155

24. Sixma HJ, Kerssens JJ, Campen CV, Peters L. Quality of care from the patients' perspective: From theoretical concept to a new measuring instrument. Health Expectations. 1998;1(2):82-95. https://doi.org/10.1046/j.1369-6513.1998.00004.x

25. Faul F, Erdfelder E, Lang AG, Buchner A. G*Power 3: A flexible statistical power analysis program for the social, behavioral, and biomedical sciences. Behavior Research Methods. 2007;39(2):175191. https://doi.org/10.3758/BF03193146

26. Choi M, Kim J. Associated factors in pediatric nurse parent partnership. Child Health Nursing Research. 2014;20(3):176-184. https://doi.org/10.4094/chnr.2014.20.3.176

27. Lee H, Kim A, Meong A, Seo M. Pediatric nurse practitioners' clinical competencies and knowing patterns in nursing: Focus group interviews. Contemporary Nurse. 2017;53(5):515-523. https://doi.org/doi.org/10.1080/10376178.2017.1315827

28. Ha YS, Lee JH, Kim SH, Kim SH, Kim SJ, Kim YY, et al. Child and adolescent health nursing. Seoul: Shinkwang Pub; 2019. p. 13-353.

29. Chao M, Shih C, Hsu SF. Nurse occupational burnout and patient-rated quality of care: The boundary conditions of emotional intelligence and demographic profiles. Japan Journal of Nursing Science. 2016;13(1):156-165. https://doi.org/10.1111/jjns.12100

30. Kang M, Ahn H, Kim E. A study of pediatric nurse's emotional labor, empowerment, pediatric nurse-caregiver partnership. Asia-Pacific Journal of Multimedia Services Convergent with Art, Humanities, and Sociology. 2017;7(7):359-367. 